\title{
Оптимизация параметров сверхрешетки для диодов терагерцового диапазона частот
}

\author{
(C) Д.Г. Павельев ${ }^{1}$, А.П. Васильев ${ }^{2}$, В.А. Козлов ${ }^{1,3}$, Е.С. Оболенская ${ }^{1}$, \\ С.В. Оболенский ${ }^{1}$, В.М. Устинов ${ }^{4}$ \\ ${ }^{1}$ Нижегородский государственный университет им. Н.И. Лобачевского, \\ 603950 Нижний Новгород, Россия \\ ${ }^{2}$ НТЦ микроэлектроники Российской академии наук, \\ 194021 Санкт-Петербург, Россия \\ ${ }^{3}$ Институт ффизики микроструктур Российской академии наук, \\ 607680 Нижний Новгород, Россия \\ ${ }^{4}$ Физико-технический институт им. А.Ф. Иоффе Российской академии наук, \\ 194021 Санкт-Петербург, Россия \\ E-mail: pavelev@rf.unn.ru
}

(Получена 27 апреля 2017 г. Принята к печати 12 мая 2017 г.)

Ранее для изготовления смесительных диодов нами применялись GaAs/AlAs сверхрешетки с малой площадью активной области $\left(\sim 1\right.$ мкм $\left.^{2}\right)$, и была установлена возможность их эффективного применения в терагерцовом диапазоне частот. Теоретически и экспериментально было показано, что на частотах до 5.3 ТГц малопериодные (содержащие небольшое число периодов) сверхрешетки в составе гармонических смесителей проявляют существенные преимущества по сравнению с многопериодными, т. е. содержащими 50-100 и больше периодов. В данной работе проведена оптимизация конструкции сверхрешеток и показано, что эффективность работы малопериодных сверхрешеток во многом определяется переходными областями, расположенными на ее краях.

DOI: 10.21883/FTP.2017.11.45097.11

\section{1. Введение}

В данной работе описаны подходы к увеличению предельной частоты диодов на основе сверхрешеток $\mathrm{GaAs}_{m} / \mathrm{AlAs}_{n}$ с малой площадью активной области $\left(\sim 1\right.$ мкм $\left.^{2}\right)$ и с омическими контактами на основе InGaAs. Использование высоколегированных сверхрешеток (CР) и омических контактов с малым приведенным сопротивлением обусловило возможность применения таких диодов в приборах с рабочими частотами вплоть до нескольких терагерц.

В работе [1] было проведено теоретическое и экспериментальное сравнение параметров малопериодных (6 периодов) и среднепериодных (18 периодов) сверхрешеток. В настоящей работе область сравнения существенно расширена, в основном в область малопериодных СР. С помощью модели Кронига-Пенни были получены значение ширины и положение середины мини-зоны для $\mathrm{CP}$ с различным количеством монослоев GaAs и $\mathrm{AlAs}$ в одном периоде сверхрешетки, а также разного количества периодов. Это позволило определить входные данные для моделирования транспорта электронов в таких структурах методом Монте-Карло. В проделанных расчетах была учтена длина СР и изменение эффективной массы электрона при переходе от одной СР к другой. В результате был подробно (за счет большего количества итераций) изучен транспорт электронов в 6-периодных СР и выяснена возможность увеличения рабочих частот приборов на сверхрешетках путем оптимизации их параметров и выбора соответствующей кон- струкции. Были рассчитаны величины тока для каждой СР и сопоставлены эффективности их работы.

Также в работе были проведены импульсные измерения вольт-амперных характеристик (BАХ) исследуемых структур, что позволило оценить влияние нагрева диода на его работу и корректно выбрать оптимальную конструкцию СР.

\section{2. Объект исследования}

На рис. 1 представлена конструкция исследуемых планарных структур: вид сверху и сбоку - в разрезе. Стрелками слева направо на рисунке показано направление тока $I$ в диоде: по левому металлическому контакту $(\mathrm{Au})$, через $\mathrm{CP}, n^{+}$-GaAs и растекание тока в правый металлический контакт. Важно, что диод разделен глубоко протравленной канавкой так, что весь основной ток протекает через СР в локализованном месте, которое указано меткой: „SL“ - это активная область диода.

Для проведения исследований методом молекулярнолучевой эпитаксии [1] были изготовлены планарные диодные структуры на СР, состоящие из 18 монослоев GaAs и 4 монослоев AlAs (рис. 2). Площадь активной области - 1 мкм ${ }^{2}$. Для эффективного ввода электронов в СР на ее краях были сформированы переходные слои (рис. 2), состоящие из чередующихся слоев AlAs и GaAs с толщинами $1 \times 28,2 \times 24$ и $3 \times 21$ монослоев [2]. Применение слоя InGaAs для снижения контактного сопротивления металл-полупроводник уменьшило 
контактное сопротивление до $\sim 2 \cdot 10^{-7} \mathrm{OM} \cdot \mathrm{cm}^{2}$. Это позволило добиться отношения сопротивления контактов к сопротивлению СР как один к двум, так что потери в диапазоне терагерцовых частот оказались приемлемыми.

Также были исследованы структуры на СР, состоящие из 2, 4, 6 монослоев AlAs и 14, 16, 18, 20 монослоев $\mathrm{GaAs}$, длины и времена пролета которых указаны в

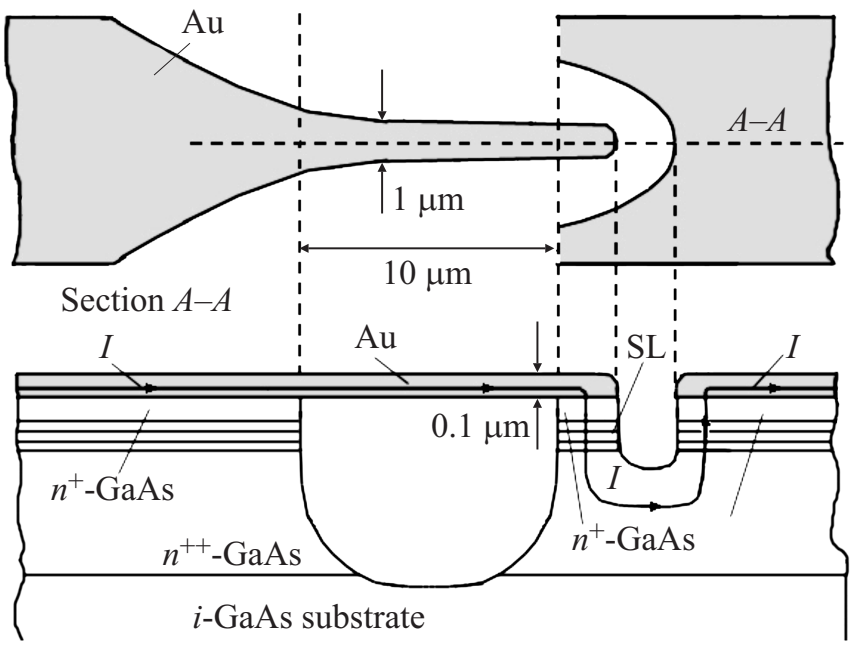

Рис. 1. Конструкция исследуемой структуры. SL - область СР, определяющая параметры диодов (активная область диода).
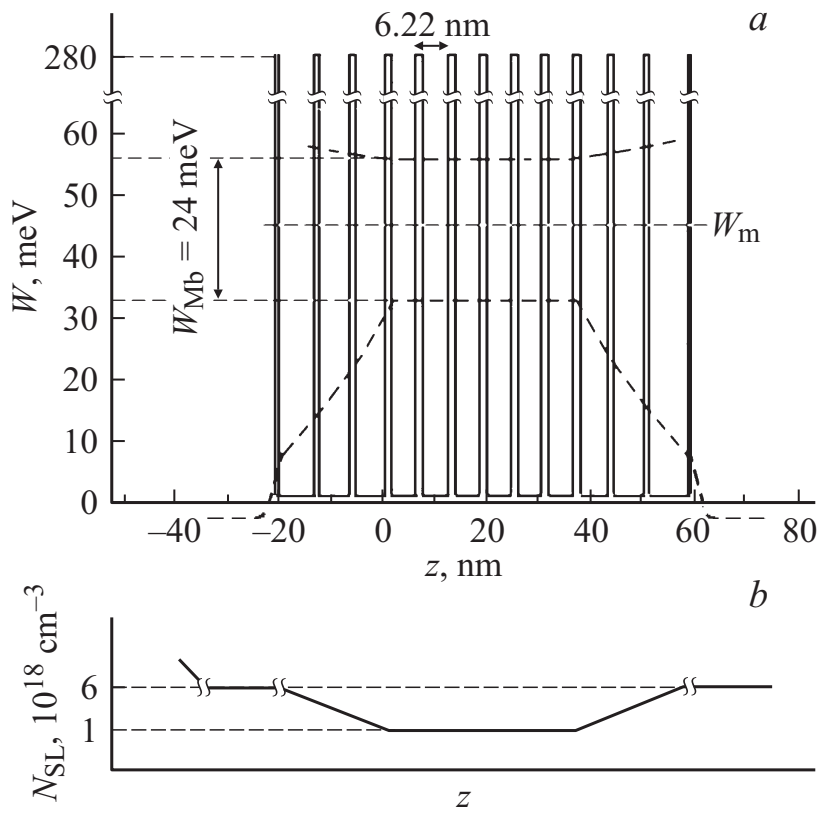

Pис. 2. Конструкция короткой диодной структуры на СР, состоящей из 18 монослоев GaAs и 4 монослоев AlAs [1] (6 периодов): $a$ - зонная диаграмма мини-зоны с учетом переходных слоев, указаны ширина $W_{\mathrm{Mb}}$ и положение середины мини-зоны $W_{m} ; b-N_{\mathrm{SL}}-$ концентрация доноров в структуре.
Таблица 1. Параметры моделируемых структур

\begin{tabular}{c|l|r|l|c|c}
\hline $\begin{array}{c}\text { Количество } \\
\text { монослоев } \\
\text { AlAs и GaAs }\end{array}$ & $\begin{array}{c}W_{m}, \\
\text { мэB }\end{array}$ & $\begin{array}{c}W_{\text {M }}, \\
\text { мэВ }\end{array}$ & $\begin{array}{c}\text { Длина } \\
\text { СР, нм }\end{array}$ & $\begin{array}{c}\text { Время } \\
\text { пролета, } \\
\text { пс }\end{array}$ & $\begin{array}{c}\text { Нормиро- } \\
\text { ванный ток }\end{array}$ \\
\hline $2 \times 14$ & 70.95 & 86.7 & 27.12 & 0.16 & 3.56 \\
$4 \times 14$ & 58.95 & 32.7 & 30.54 & 0.23 & 0.867 \\
$6 \times 14$ & 56.85 & 13.8 & 33.9 & 0.29 & 0.33 \\
$2 \times 16$ & 60.3 & 72 & 30.5 & 0.189 & 3.4761 \\
$4 \times 16$ & 51.2 & 27.3 & 33.9 & 0.265 & 0.943 \\
$6 \times 16$ & 49.5 & 11.4 & 37 & 0.316 & 0.3716 \\
$2 \times 18$ & 52 & 60.9 & 33.9 & 0.221 & 3.3934 \\
$4 \times 18$ & 44.85 & 23.1 & 37 & 0.305 & 1 \\
$6 \times 18$ & 43.5 & 9.6 & 40.68 & 0.397 & 0.4003 \\
$2 \times 20$ & 45.6 & 52.2 & 37 & 0.253 & 3.2723 \\
$4 \times 20$ & 39.8 & 20.1 & 40.68 & 0.361 & 1.0489 \\
$6 \times 20$ & 38.7 & 8.4 & 44 & 0.457 & 0.4272
\end{tabular}

табл. 1. Это позволило сравнить между собой параметры структур на СР в зависимости от соотношения количества различных монослоев. Самой короткой исследуемой структурой являлась сверхрешетка, состоящая из шести периодов, каждый из которых представлял собой 2 монослоя AlAs и 14 монослоев GaAs. Самая длинная структура - шесть периодов, каждый из которых состоит из 6 монослоев AlAs и 20 монослоев GaAs соответственно.

\section{3. Результаты эксперимента}

С целью определения степени влияния разогрева сверхрешеток протекающим током на их параметры проводились экспериментальные исследования импульсных вольт-амперных характеристик сверхрешеток.

Схема импульсного измерительного стенда была рассмотрена подробно ранее в работе [2]. Для формирования сигнала использовался генератор прямоугольных и пилообразных импульсов, исследуемые образцы устанавливались в зондовую систему, которая подключалась к генератору импульсов. Результаты измерений регистрировались цифровым осциллографом. Для получения более точного результата проводилось усреднение измеренных ВАХ по 100 измерениям.

Использовались два типа измерительных сигналов: 1) прямоугольный импульс - длительность импульса составляла $50 \mathrm{Hc}-50$ мкс, период - $100 \mathrm{м \kappa c,}$ фронт и спад импульса имели длительность 15-20 нс; 2) пилообразный импульс - период сигнала составлял 2 мкс-100 мс, а длительность импульса совпадала с периодом. Сопоставляя значения напряжения на исследуемом образце и напряжения на последовательно подключенном измерительном сопротивлении, регистрируемые осциллографом в один и тот же момент времени, были получены BAX исследуемых структур. Благодаря специальной калибровке задержки импульсов напряжения 


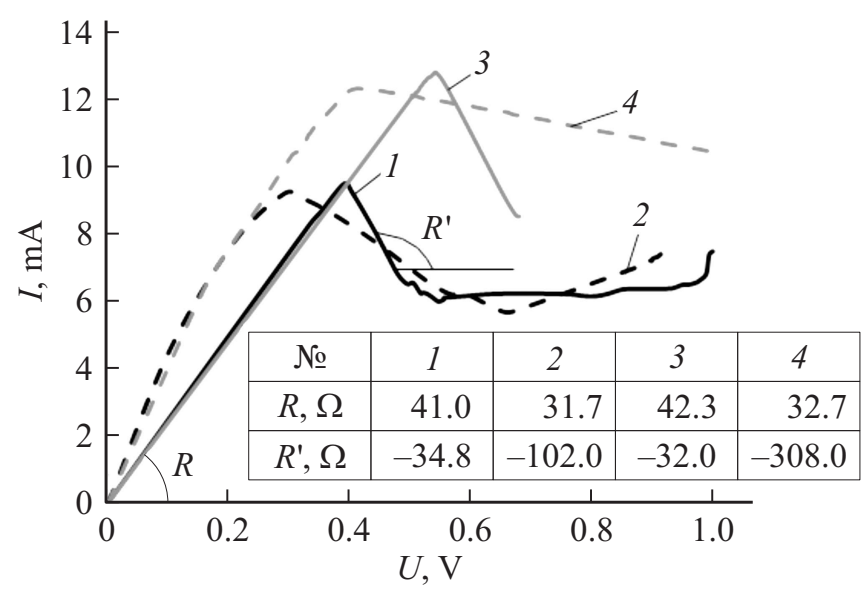

Рис. 3. ВАХ исследуемых структур: 1,2 - результаты измерений 6-периодных $\mathrm{CP} ; 3,4$ - результаты измерений 18-периодных СР. Вид измерительного сигнала: 1, 3 - прямоугольный импульс длительностью 50 нс (скважность 1/2000), 2,4 - пила. Период следования измерительных импульсов: $1,3-100$ мкс; 2, $4-100$ мс. На вставке представлены результаты расчета сопротивления для разных участков, ВАХ, где в первой строке указан номер кривой, $R$ - сопротивление начального участка $\mathrm{BAX}, R^{\prime}-$ сопротивление участка с отрицательным наклоном на ВАХ.

в сигнальных линиях измерительного стенда удалось минимизировать искажения получаемой ВАХ.

Сравнение ВАХ и проведенные аналитические оценки теплового сопротивления образцов показали, что при использовании прямоугольных импульсов, за счет низкой (1/2000) скважности, удавалось избежать существенного нагрева исследуемых структур. В случае пилообразного сигнала осуществлялась плавная регулировка температуры образца, а при длительностях импульса более 50 мс зависимость температуры активной области образца от времени повторяла ход зависимости тока образца от времени.

Вид экспериментальных импульсных ВАХ диодных структур приведен на рис. 3. Были исследованы по 20 штук средне- и малопериодных СР с числом периодов 18 и 6. При этом соотношение монослоев AlAs и GaAs выбиралось равным $4 \times 18$. Результаты измерений показали хорошую повторяемость, так что был сделан вывод об адекватности полученных результатов.

Из результатов эксперимента видно, что использование прямоугольных импульсов низкой скважности существенно снижает разогрев, так что величина отрицательного сопротивления диодов становится максимальной (см. вставку на рис. 3). Использование пилообразного импульса с периодом 100 мс приводило к максимальному увеличению температуры образцов, причем нагрев влиял и на начальный участок ВАХ.

Результаты измерений позволили точнее калибровать компьютерную модель, чем это было сделано в работе [3], что позволило провести оптимизацию конструкции диодов корректно.

\section{4. Математическая модель, результаты расчетов и их обсуждение}

Для оптимизации конструкции СР проводилось моделирование транспорта электронов для различных СР, состоящих из 2, 4, 6 монослоев AlAs и 14, 16, 18 или 20 монослоев GaAs. Расчет параметров мини-зоны в СР и переходных слоях проводился на основе модели Кронига-Пенни (табл. 1) и сопоставления положения мини-зоны в бесконечной СР с положением уровней в отдельных квантовых ямах конечной глубины. Детально этот подход обсуждался в работе [1].

С помощью расчета функции Ферми-Дирака в слое $n^{+}$-GaAs, инжектирующего электроны в сверхрешетку, и сопоставления этих данных с положением и шириной мини-зоны СР было определено соотношение величины инжектированного тока для $\mathrm{CP}$, состоящих из различного количества монослоев AlAs и GaAs (табл. 1). Bce значения, представленные в столбце тока, были нормированы на значение тока для СР, состоящей из 4 монослоев AlAs и 18 монослоев GaAs, для которой экспериментально определялась степень разогрева.

Для моделирования транспорта электронов в малопериодных и среднепериодных СР применялись квазигидродинамическое приближение и метод МонтеКарло [4,5], в котором учитывалась зонная диаграмма CP. Сначала проводились расчеты в рамках квазигидродинамической модели, состоящей из уравнений баланса энергии и импульса. Затем - моделирование методом Монте-Карло.

С помощью квазигидродинамической модели для различного соотношения монослоев в СР были рассчитаны средняя скорость, пороговое поле, т. е. поле, при котором начинается участок отрицательной дифференциальной проводимости на ВАХ, и время пролета электроном исследуемой структуры. Результаты расчета представлены в табл. 2. Видно, что чем меньше длина исследуемой СР, тем выше пороговое поле и скорость электрона, но меньше время пролета. Следовательно, необходимо уменьшать длины исследуемых СР, потому что это позволяет увеличивать предельную частоту работы исследуемых диодов.

Методом Монте-Карло проводился расчет зависимости средней скорости электронов от координаты. В табл. 1 показаны параметры мини-зоны, использованные для расчета зависимости скорости, приведенной на рис. 4. Также при расчетах было учтено изменение эффективной массы в СР, так как это делалось ранее в работе [1]. Видно, что параметры СР существенно влияют на скорость электронов, но, как показали расчеты, изменение параметров переходных слоев СР влияет на скорость и концентрацию электронов в 1.5-2 раза сильнее.

В результате расчетов методом Монте-Карло была получена зависимость скорости от координаты, которая приведена на рис. 4. Видно, что чем выше середина мини-зоны и напряженность поля в сверхрешетке, тем 
Таблица 2. Средняя скорость, поле и время пролета электроном СР

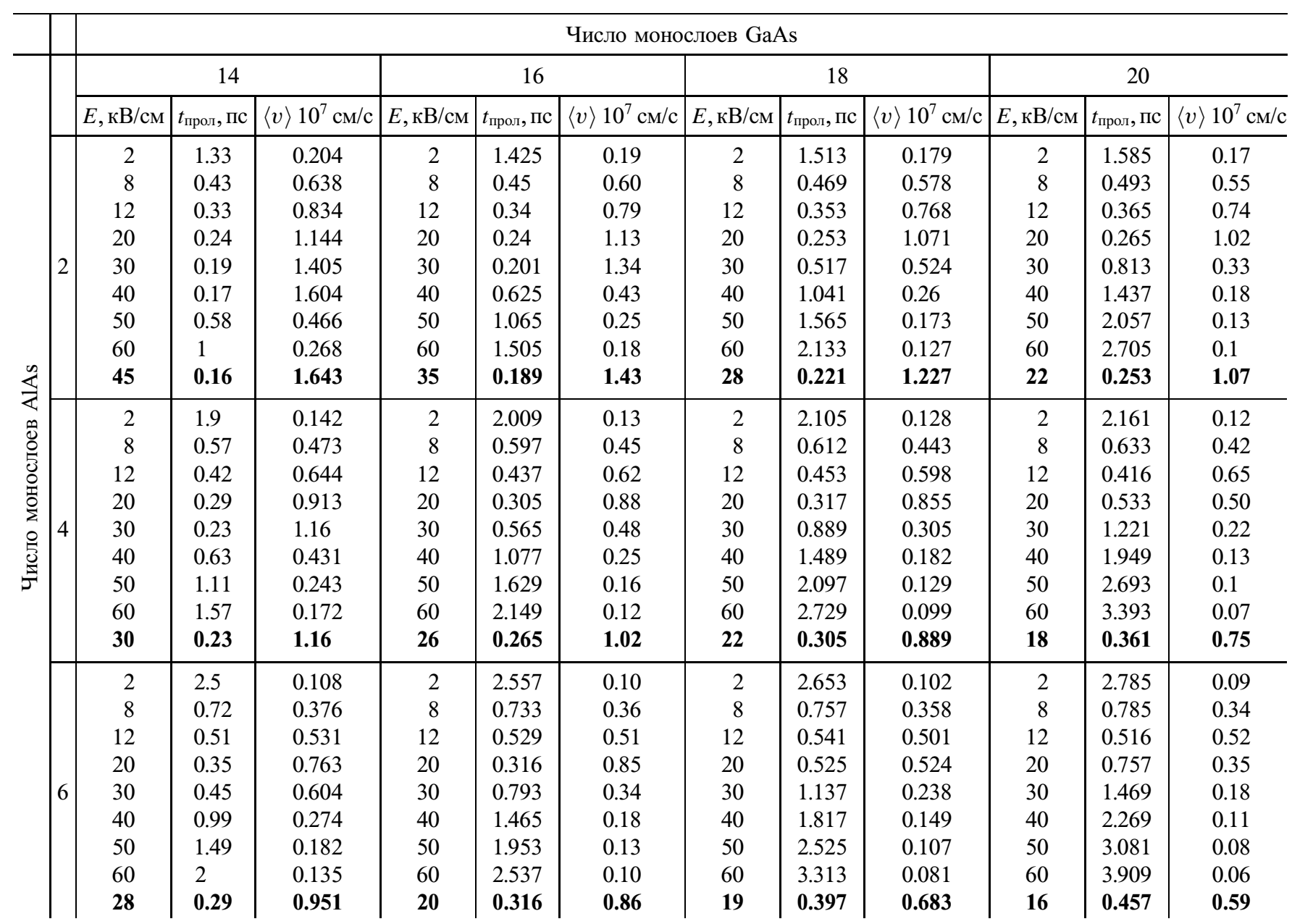

Примечание. Данные получены из расчетов с помощью квазигидродинамической модели. Жирным шрифтом выделены значения, соответствующие пороговому полю (поле, при котором начинается участок отрицательной дифференциальной проводимости на вольт-амперной характеристике).

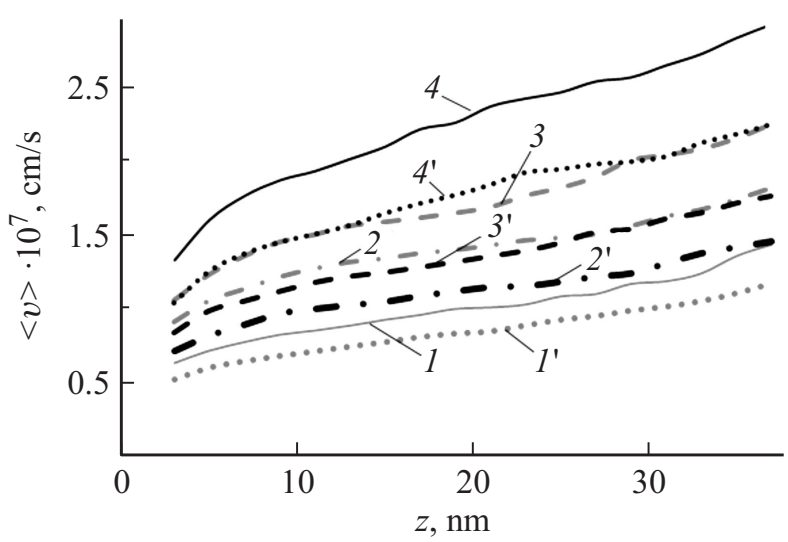

Рис. 4. Полученная методом Монте-Карло средняя скорость электронов в зависимости от координаты при концентрации доноров $10^{18} \mathrm{~cm}^{-3}$ для различного положения середины минизоны $W_{m}$ и напряженности поля в сверхрешетке $E_{\mathrm{SL}}: 1-$ $W_{m}=52 \mathrm{мэB}, E_{\mathrm{SL}}=2 \kappa \mathrm{B} / \mathrm{cm} ; 1^{\prime}-W_{m}=43.5 \mathrm{мэB}, E_{\mathrm{SL}}=2 \kappa \mathrm{K} / \mathrm{cm}$; $2-W_{m}=52 \mathrm{мэ}, \quad E_{\mathrm{SL}}=8 \mathrm{\kappa B} / \mathrm{cм} ; 2^{\prime}-W_{m}=43.5 \mathrm{мэB}$, $E_{\mathrm{SL}}=8 \kappa \mathrm{B} / \mathrm{cm} ; 3-W_{m}=52 \mathrm{м} \ni, \quad E_{\mathrm{SL}}=12 \kappa \mathrm{K} / \mathrm{cm} ; 3^{\prime}-$ $W_{m}=43.5 \mathrm{м \ni B}, E_{\mathrm{SL}}=12 \kappa \mathrm{B} / \mathrm{cm} ; 4-W_{m}=52 \mathrm{мэB}, E_{\mathrm{SL}}=20 \kappa \mathrm{K} / \mathrm{cm}$; $4^{\prime}-W_{m}=43.5 \mathrm{MэB}, E_{\mathrm{SL}}=20 \mathrm{\kappa B} / \mathrm{cm}$. выше средняя скорость электронов в исследуемой СР. Аналогичные расчеты были проведены и для других количеств монослоев GaAs и AlAs, которые указаны в табл. 1 .

В работе [3] было установлено, что в малопериодных СР определяющую роль в транспортных свойствах играет соотношение между ансамблем квазибаллистических электронов, претерпевающих только малоугловые рассеяния (дает основной вклад в электрический ток), и ансамблем электронов, формирующим объемный заряд из-за сильного рассеяния. В данной работе показано, что формирование указанных ансамблей осуществляется не только самой $\mathrm{CP}$, но также и ее переходными слоями, согласующими СР с объемным GaAs, примыкающими к сверхрешетке.

В работе [6] было показано, что появление баллистических электронов в малопериодных СР приводит к возможности образования терагерцевой динамической отрицательной проводимости. Проведенные в данной работе расчеты подтвердили этот факт и позволили предложить усовершенствованную конструкцию СР - 
наиболее оптимальной конструкцией которой представляется сверхрешетка с соотношениями слоев $\mathrm{GaAs}$ и AlAs как 14-18 на 4. Указанное соотношение позволяет разумно сочетать величину разогрева сверхрешетки, неминуемо возникающую при работе в непрерывном режиме, с достаточной амплитудой терагерцового сигнала, позволяющей реализовывать смесители и генераторы на исследуемых образцах СР. Возможно повышение предельных характеристик СР за счет использования более коротких структур с соотношением слоев GaAs и AlAs как $14 \times 3$. Сравнение времен пролета электронами $\mathrm{CP}$ для соотношения слоев $\mathrm{AlAs}$ и $\mathrm{GaAs}$ как $4 \times 18$ и $2 \times 14$ показывает, что возможно увеличение предельных частот работы СР до 8-10 ТГц.

\section{5. Заключение}

В данной работе теоретически и экспериментально исследованы диоды на основе СР с различным соотношением слоев AlAs и GaAs. Можно сделать вывод, что для детального измерения вольт-амперных характеристик исследуемых диодов на основе СР необходимо применять импульсный метод измерений, который минимизирует нагрев структур. Этот метод также позволяет наблюдать ступеньки на вольт-амперной характеристике, которые были обсуждены в работе [3].

Появление баллистических электронов [6] в малопериодных СР приводит к возможности образования терагерцевой динамической отрицательной проводимости, что и показали расчеты, в результате которых видно, что при уменьшении длины СР происходит уменьшение времени пролета СР и увеличение скорости электронов. Это позволит добиться увеличения предельных частот работы диодов на таких структурах.

Дальнейшее совершенствование сверхрешеток для терагерцового диапазона, по-видимому, потребует проведения дополнительных экспериментов, разработки нового дизайна СР и ее структуры.

Работа поддержана грантами РФФИ № 14-02-00581, 15-02-07935 и МОН РФ (соглашение от 27 августа 2013 г. № 02.B.49.21.0003), а также государственным заданием МОН РФ (код проекта 2183) и госзаданием МОН РФ (3.3854.2017/4.6).

\section{Список литературы}

[1] Д.Г. Павельев, А.П. Васильев, В.А. Козлов, Ю.И. Кошуринов, Е.С. Оболенская, С.В. Оболенский, В.М. Устинов. Журн. радиоэлектрон., 1, 1 (2016).

[2] Е.С. Оболенская, А.Ю. Чурин, С.В. Оболенский, А.В. Мурель, В.И. Шашкин. ФТП, 49 (11), 1507 (2015).

[3] Д.Г. Павельев, А.П. Васильев, В.А. Козлов, Ю.И. Кошуринов, Е.С. Оболенская, С.В. Оболенский, В.М. Устинов. ФТП, 50 (11), 1548 (2016).
[4] Д.Г. Павельев, Н.В. Демарина, Ю.И. Кошуринов, А.П. Васильев, Е.С. Семенова, А.Е. Жуков, В.М. Устинов. ФТП, 38 (9), 1141 (2004).

[5] S.V. Obolensky, A.V. Murel, N.V. Vostokov, V.I. Shashkin. IEEE Trans. Electron Dev., 58 (8), 2507 (2011).

[6] V.A. Kozlov, A.V. Nikolaev, A.V. Samokhvalov. Semicond. Sci. Technol., 19 (4), S99 (2004).

Редактор А.Н. Смирнов

\section{Optimization of paramteres of the superlattice diodes terahertz frequency range}

\author{
D.G. Pavelyev' ${ }^{1}$, A.P. Vasilev', V.A. Kozlov',3, \\ E.S. Obolenskaya ${ }^{1}$, S.V. Obolensky' ${ }^{1}$, V.M. Ustinov ${ }^{4}$ \\ ${ }^{1}$ Lobachevsky State University of Nizhny Novgorod, \\ 603950 Nizhny Novgorod, Russia \\ ${ }^{2}$ Submicron Heterostructures for Microelectronics, \\ Research \& Engineering Center, \\ Russian Academy of Sciences, \\ 194021 St. Petersburg, Russia \\ ${ }^{3}$ Institute for Physics of Microstructures, \\ Russian Academy of Sciences, \\ 603087 Nizhny Novgorod, Russia \\ ${ }^{4}$ Ioffe Institute, \\ 194021 St. Petersburg, Russia
}

Abstract Earlier, GaAs/AlAs superlattice (SL) with a small active area $\left(\sim 1 \mathrm{~mm}^{2}\right)$ were investigated and the possibility of its effective application in the terahertz frequency range were established. Theoretically and experimentally short SL composed of harmonic mixers at frequencies up to $5.3 \mathrm{THz}$ exhibit significant advantages in comparison with the long-period containing 50-100 periods. In this paper, the optimization of the structure SL was performed and it was shown that the efficiency of short SL determined by the transition region located at the edges. 